\title{
Padronização da técnica de imuno-histoquímica para raiva em amostras de tecido do sistema nervoso central de bovinos fixadas em formol e emblocadas em parafina ${ }^{1}$
}

\author{
Pedro M.O. Pedroso², Caroline A. Pescador ${ }^{2}$, Paulo M. Bandarra², Djeison L. \\ Raymundo ${ }^{2}$, Mauro R. Borba ${ }^{2}$, Flademir Wouters ${ }^{3}$, Pedro S. Bezerra Júnior ${ }^{3}$ e \\ David Driemeier $2^{*}$
}

\begin{abstract}
Pedroso P.M.O., Pescador C.A., Bandarra P.M., Raymundo D.L., Borba M.R., Wouters F., Bezerra Jr P.S. \& Driemeier D. 2008. [Standardization of immunohistochemistry technique for detection of rabies virus in formalin-fixed and paraffin-embedded tissue samples from central nervous system of cattle.] Padronização da técnica de imuno-histoquímica para raiva em amostras de tecido do sistema nervoso central de bovinos fixadas em formol e emblocadas em parafina. Pesquisa Veterinária Brasileira 28(12):627-632. Setor de Patologia Veterinária, Faculdade de Veterinária, Universidade Federal do Rio Grande do Sul, Av. Bento Gonçalves 9090, Porto Alegre, RS 91540-000, Brazil. E-mail: davetpat@ufrgs.br

For standardization of the rabies immunohistochemistry technique, five samples of central nervous system (CNS) of cattle naturally infected with rabies virus were examined. One polyclonal antibody and two monoclonal antibodies were used. The following reagents were evaluated for antigen retrieval: XIV protease, proteinase $\mathrm{K}$ and citrate buffer $(\mathrm{pH}$ 6.0) boiling at $100^{\circ} \mathrm{C}$ during 15 minutes in bain-marie. Detection of rabic antigen was possible with the three antibodies tested. The polyclonal antibody was superior to the monoclonal antibodies, demonstrating good results with the three antigen retrieval protocols. The highest intensity staining was obtained with the citrate buffer and heat. The immunohistochemistry technique demonstrated the presence of viral antigens in the cytoplasm of neurons, in form of aggregates or with round or oval shape. The antigens were found as single or multiples inclusion bodies in the neurons. Immunohistochemistry is a fast method that can be used in routine procedures in cases where rabies is suspected, especially when the brain is submitted to the laboratory as formalin-fixed fragments or when samples could not be immediately shipped. The technique is also useful for retrospective studies.
\end{abstract}

INDEX TERMS: Diseases of cattle, infectious diseases, diseases of the central nervous system, rabies, immunohistochemistry standardization.

RESUMO.- Para a padronização da técnica de imunohistoquímica para raiva foram utilizadas cinco amostras de SNC de bovinos infectados naturalmente com o vírus da raiva usando-se um anticorpo policlonal e dois mono-

\footnotetext{
${ }^{1}$ Recebido em 23 de maio de 2008.

Aceito para publicação em 18 de julho de 2008.

2 Setor de Patologia Veterinária (SPV), Departamento de Patologia Clínica Veterinária, Faculdade de Veterinária, Universidade Federal do Rio Grande do Sul (UFRGS), Av. Bento Gonçalves 9090, Porto Alegre, RS 95320-000, Brasil. *Autor para correspondência: davetpat@ufrgs.br

3 SPV, Departamento de Patologia Veterinária, Universidade Federal de Lavras (UFLA), Cx.Postal 3037, Lavras, MG 37200-000, Brasil.
}

clonais. Para a recuperação antigênica foram avaliados os seguintes reagentes: protease XIV, proteinase $\mathrm{Ke}$ tampão citrato $\mathrm{pH} 6,0$ mantido a $100^{\circ} \mathrm{C}$ por 15 minutos. A detecção de antígeno rábico nas amostras foi possível com os três anticorpos utilizados. O anticorpo policlonal foi superior aos anticorpos monoclonais, demonstrando bons resultados com os três protocolos de recuperação antigênica, obtendo uma maior intensidade de marcação quando utilizado o tampão citrato e calor. A técnica de imuno-histoquímica demonstrou a presença do antígeno viral no citoplasma de neurônios na forma de agregados de grânulos ou de forma redonda ou oval, mostrando cor- 
púsculo de inclusão viral único a múltiplos nos neurônios. A imuno-histoquímica é um método rápido, podendo ser usada na rotina em casos onde inicialmente há suspeita de raiva, especialmente em casos onde fragmentos de cérebro submetidos ao laboratório foram fixados em formol, onde as amostras não podem ser enviadas ao laboratório imediatamente e para a realização de estudos retrospectivos.

TERMOS DE INDEXAÇÃO: Doenças de bovinos, doenças infecciosas, doenças do sistema nervoso, raiva, padronização de imuno-histoquímica.

\section{INTRODUÇÃO}

A raiva é causada por um vírus RNA, envelopado (Swanepoel 2004), da ordem Mononegavirales, família Rhabdoviridae e gênero Lyssavirus (Consales \& Bolzan 2007) e é altamente neurotrópico (George 1993, Woldehiwet 2002). Embora todos os mamíferos sejam susceptíveis, canídeos e morcegos são considerados como os vetores mais eficientes da enfermidade (Woldehiwet 2002).

No Brasil, Desmodus rotundus é a principal espécie de morcego hematófago que transmite a raiva para bovinos, porém outras espécies (Diaemus youngi e Diphylla ecaudata) podem ocasionalmente transmitir, a doença (Fernandes \& Riet-Correa 2007). A raiva bovina ocorre em todo o Brasil e tem importância na maioria dos Estados, tanto pelo caráter de zoonose como por causar perdas econômicas na pecuária. Anualmente as perdas de bovinos por raiva são estimadas em aproximadamente 850.000 cabeças, que equivalem aproximadamente a 17 milhões de dólares (Lima et al. 2005). Em bovinos no Brasil, predomina a forma paralítica, caracterizada por paresia e paralisia ascendentes (Langohr et al. 2003). As lesões histológicas de raiva são geralmente limitadas ao sistema nervoso central (Jubb \& Huxtable 1993, Jones et al. 2000), glânglios e nervos cranianos e espinhais (Swanepoel 2004) e caracterizam-se por meningoencefalomielite não-purulentas (Fernandes \& Riet-Correa 2007) com ganglioneurite mononuclear (Swanepoel 2004).

O suporte laboratorial é imprescindível para o diagnóstico da doença e a técnica de Imunofluorescência Direta (IFD) em tecidos refrigerados ou congelados o teste padrão utilizado devido a sua rapidez e acurácia (Zimmer et al. 1990). Outro teste utilizado é a inoculação intracerebral em camundongos que apesar de ser mais específica, tem a desvantagem de ser demorada quando comparada a IFD (Germano et al. 1977).

A comparação entre métodos histoquímicos, de imunofluorescência direta e de inoculação intracerebral em camundongos tem revelado maior concordância entre imunofluorescência e inoculação intracerebral em camundongos, embora ocorram, esporadicamente resultados falsos negativos ora em uma, ora em outra técnica (Côrtes et al. 1979).

O objetivo da padronização da técnica de imuno-histoquímica para raiva foi estabelecer um protocolo padrão de diagnóstico para fragmentos de sistema nervoso central que chegam previamente fixados em formol $10 \%$ ao Setor de Patologia Veterinária da Universidade Federal do Rio Grande do Sul. Contribuindo assim para o diagnóstico de doenças do SNC de bovinos, como parte do programa DXSNC de vigilância da Encefalopatia Espongiforme Bovina (EEB) coordenada pelo Programa Nacional de Controle da Raiva dos Herbívoros e outras encefalopatias (PNCRH) do Ministério da Agricultura Pecuária e Abastecimento (MAPA).

\section{MATERIAL E MÉTODOS}

Foram utilizadas amostras de sistema nervoso central (SNC) de 2 bovinos registrados no arquivo do programa DXSNC do MAPA do Setor de Patologia Veterinária da Universidade Federal do Rio Grande do Sul (SPV-UFRGS) e três amostras enviadas pelo Setor de Patologia Veterinária da Universidade Federal de Lavras (SPV-UFLA) de necropsias de casos de bovinos infectados naturalmente com raiva, os quais obtiveram resultados positivos nos testes de imunofluorescência direta (IFD) e na prova de inoculação intracerebral em camundongos (IIC).

Uma amostra do tronco cerebral de cada bovino necropsiado foi fixada em formol $10 \%$, processada rotineiramente para exame histopatológico, incluída em parafina, cortada a $5 \mathrm{zm}$ de espessura e coradas pela hematoxilina-eosina (HE) (Prophet et al. 1992). Dados sobre os históricos, quadro clínico dos animais afetados foram obtidos com o veterinário requisitante ou pela própria equipe do SPV.

Para a padronização da técnica de imuno-histoquímica para raiva foram feitos cortes histológicos de $5 \mathrm{Pm}$ de espessura e aplicados sobre lâminas positivadas (ImmunoSlide-EasyPath), secadas verticalmente em temperatura ambiente, antes de aquecê-las em estufa a $60^{\circ} \mathrm{C}$ por 3-4 horas. Após os cortes foram desparafinados em xilol e reidratados em graduações decrescentes de álcool até a água destilada. O bloqueio da peroxidase endógena foi feito pela incubação das lâminas em solução de peróxido de hidrogênio a 3\% em água destilada por 15 minutos em temperatura ambiente, sendo posteriormente lavadas em água destilada três vezes por dois minutos. Para a recuperação antigênica foram avaliados os seguintes reagentes: protease XIV (Sigma Chemical Company, Poole, UK), proteinase K (DAKO Corporation, Carpinteria, USA) e tampão Citrato $(2,1 \mathrm{~g}$ de ácido cítrico em 1 litro de água destilada, ajustando o $\mathrm{pH}$ em $6,0 \mathrm{com} \mathrm{NaOH}$ a 0,5\%). As lâminas tratadas com protease XIV a $0,005 \%$ em PBS (phosphate buffered saline) (pH 7,4) foram incubadas em câmara úmida por 15 minutos em temperatura ambiente. Os cortes tratados com proteinase $\mathrm{K}$ foram preparados com 40ml (uma gota) da solução diluída em $2 \mathrm{ml}$ 0,05M TrisHCL pH 7,5 por 1 minuto em câmara úmida e temperatura ambiente. As lâminas tratadas com tampão citrato $10 \mathrm{mM}(\mathrm{pH} 6,0)$, foram colocadas em jarras de coloração de polipropileno durante 15 minutos em banho-maria em panela de uso comercial de aço inox com dimensões de 24x20x20cm (altura x largura x comprimento) com capacidade para dois litros previamente aquecido atingindo uma temperatura de $100^{\circ} \mathrm{C}$. Logo após as lâminas foram esfriadas por 5 minutos em temperatura ambiente.

Para a diminuição das ligações inespecíficas ("background"), os cortes foram tratados com leite desnatado (Molico) $5 \%$ diluído em água destilada durante 15 minutos. Os cortes foram cobertos com solução contendo o anticorpo primário. Foram utilizadas as diluições de 1:500 e 1:1000 em PBS para cada um dos anticorpos 
testados. Foram avaliados dois anticorpos monoclonais anti-raiva (GeneTex GTX21002 e Biodesign C86307M) e um anticorpo policlonal (anti-rabies polyclonal Chemicon \#5199) recomendado para imunofluorescência direta adaptado de Rech (2007]. Os cortes testados com os anticorpos monoclonais foram incubados em câmara úmida por $12-14$ horas ("overnight") a $4^{\circ} \mathrm{C}$ e os testados com o anticorpo policlonal foram incubados em câmara úmida a $37^{\circ} \mathrm{C}$ por 60 minutos. Posteriormente, foram lavados em água destilada e tratados com anticorpo secundário biotinalado (DAKO LSAB 2 kit, DAKO Corp., Carpinteria, CA) por 20 minutos em câmara úmida e temperatura ambiente. Logo após foram lavados em água destilada e tratados com o conjugado Streptavidina-peroxidase (DAKO Corp., Carpinteria, CA) por mais 20 minutos cada em câmara úmida e temperatura ambiente, sendo lavados novamente em água destilada e submetidos à revelação com o cromógeno vermelho (VECTOR ${ }^{\circledR}$ NovaRED) por 5 minutos. Os cortes foram lavados em água destilada e contracorados com hematoxilina de Harris por 1 minuto, posteriormente lavadas em água corrente por 1-2 minutos e desidratados em graduações de álcool, clarificadas em xilol e montadas com Entellan (Merck, Darmstadt, Germany Sigma Chemical Co., Saint Louis, USA). Em seguida as lâminas foram avaliadas em microscópio óptico e classificadas de acordo com a intensidade de marcação em 0 (ausente), 1 (leve), 2 (moderado) e 3 (acentuado). Foi inserido em cada imuno-histoquímica um controle de SNC de bovino previamente negativo nas provas de imunofluorescência direta e inoculação intracerebral em camundongos.

\section{RESULTADOS}

Os bovinos deste estudo apresentaram um quadro clínico caracterizado por incoordenação, paresia e paralisia dos membros posteriores, decúbito e morte. Todas as cinco amostras analisadas caracterizaram-se na histologia por meningoencefalomielite não-supurativa, com presença de manguitos perivasculares, microgliose e presença de corpúsculos de inclusão viral intracitoplasmáticos em neurônios. O teste de imunofluorescência direta para raiva e inoculação intracerebral em camundongos foi positivo em todos os casos analisados e serviu de padrão para avaliação do método imuno-histoquímico.

A detecção de antígeno rábico nas amostras analisadas foi possível com os três anticorpos utilizados. Em geral, os resultados usando o anticorpo policlonal foram superiores aos anticorpos monoclonais. O anticorpo policlonal (Chemicon \#5199) demonstrou bons resultados com os três protocolos de recuperação antigênica, porém teve maior intensidade de marcação quando utilizado calor com solução de tampão citrato, obtendo-se grau de marcação acentuado nos casos testados (Fig.1). Podemse identificar marcação no pericário, axônios (Fig.2) e algumas vezes em dendritos dos neurônios. Recuperação antigênica com protease XIV e proteinase $\mathrm{K}$ obtiveram intensidade de marcação semelhantes, prevalecendo uma marcação moderada em ambos tratamentos enzimáticos. No Quadro 1 estão representados os graus de intensidade de marcação imuno-histoquímica com o anticorpo policlonal nos cinco casos analisados no presente estudo.

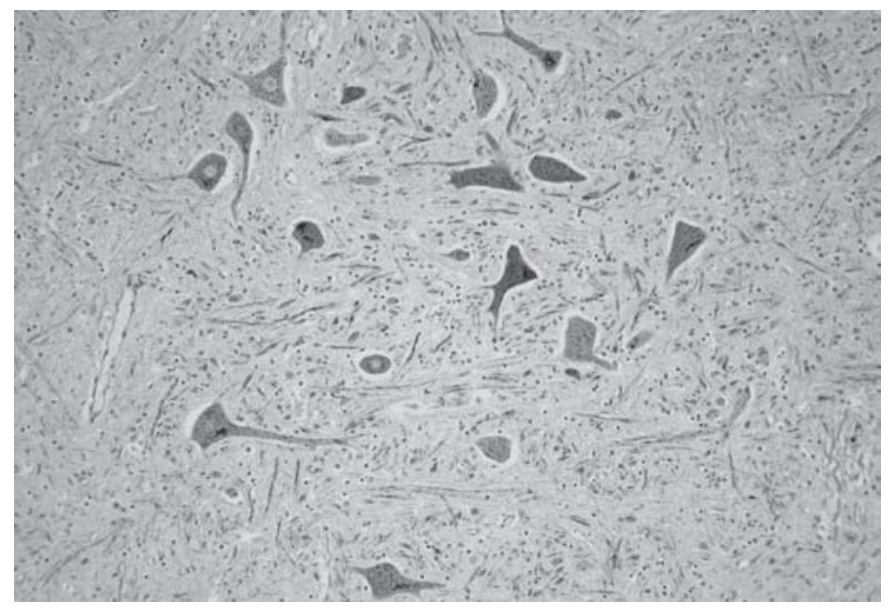

Fig.1. Marcação positiva acentuada vermelha em neurônios da medula espinhal. Recuperação antigênica com calor e tampão citrato. Anticorpo policlonal Chemicon 1:1000. Imunohistoquímica pelo método biotina-estreptavidina-peroxidase e contra-corada com hematoxilina, obj.20x.

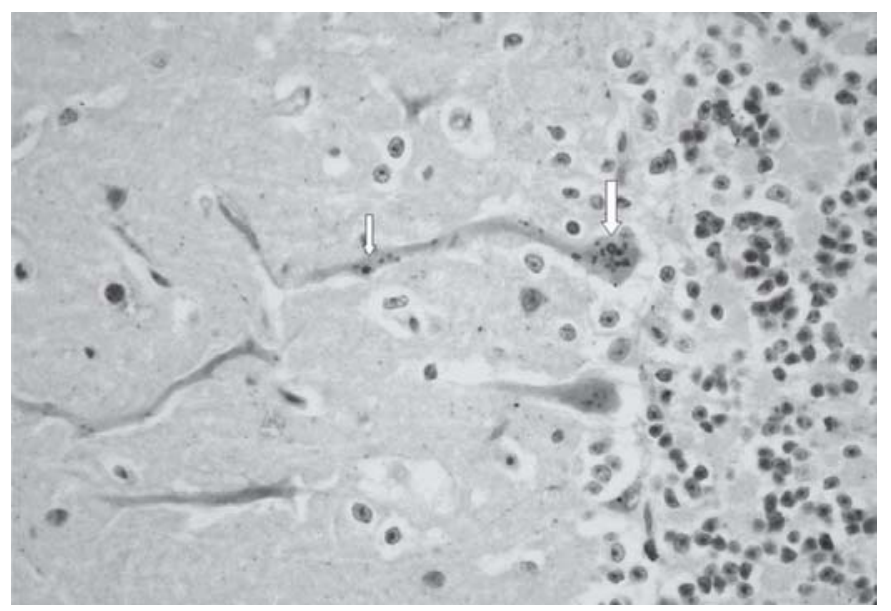

Fig.2. Marcação positiva vermelha em corpúsculos de inclusão viral no pericário (seta maior) e axônio (seta menor) de célula de Purkinje do cerebelo. Anticorpo policlonal Chemicon 1:1000. Imuno-histoquímica pelo método biotina-estreptavidina-peroxidase e contra-corada com hematoxilina, obj.40x.

\section{Quadro 1. Resultados imuno-histoquímicos obtidos com a utilização do anticorpo policlonal (Chemicon \#5199) usando três recuperações antigênicas}

\begin{tabular}{ccccccccc}
\hline Caso no. & \multicolumn{2}{c}{ Protease XIV } & & \multicolumn{2}{c}{ Proteinase K } & & \multicolumn{2}{c}{ Calor (Tampão Citrato) } \\
\cline { 2 - 4 } & $1 / 500$ & $1 / 1000$ & & $1 / 500$ & $1 / 1000$ & & $1 / 500$ & $1 / 1000$ \\
\hline 1 & $2^{\mathrm{a}}$ & 2 & 2 & 2 & 3 & 3 \\
2 & 2 & 2 & 2 & 2 & & 3 & $1^{\mathrm{b}}$ \\
3 & 2 & 2 & 2 & 2 & & $3^{\mathrm{C}}$ & 3 \\
4 & 1 & 1 & 1 & 1 & 3 & 3 \\
5 & 3 & 1 & 2 & 1 & & 3 & 3 \\
$6^{\mathrm{d}}$ & $0^{\mathrm{e}}$ & 0 & 0 & 0 & & 0 & 0
\end{tabular}

a Marcação moderada, b marcação leve, c marcação acentuada, ${ }^{d}$ controle negativo, e ausência de marcação. 


\section{Quadro 2. Resultados imuno-histoquímicos obtidos com a utilização do anticorpo monoclonal GeneTex (GTX 21002) usando três recuperações antigênicas}

\begin{tabular}{ccccccccc}
\hline Caso no. & \multicolumn{2}{c}{ Protease XIV } & & \multicolumn{2}{c}{ Proteinase K } & & \multicolumn{2}{c}{ Calor (Tampão Citrato) } \\
& $1 / 500$ & $1 / 1000$ & & $1 / 500$ & $1 / 1000$ & & $1 / 500$ & $1 / 1000$ \\
\hline 1 & $1^{\mathrm{a}}$ & 1 & & 1 & 1 & & $0^{\mathrm{b}}$ & 0 \\
2 & 1 & 1 & & 1 & 1 & & 0 & 0 \\
3 & 1 & 0 & & 0 & 0 & & 0 & 0 \\
4 & 0 & 0 & & 0 & 0 & & 0 & 0 \\
5 & 1 & 1 & & 1 & 1 & & 0 & 0 \\
$6^{\mathrm{C}}$ & 0 & 0 & 0 & 0 & & 0 & 0
\end{tabular}

a Marcação leve, b ausência de marcação, c controle negativo.

Quadro 3. Resultados imunohistoquímicos obtidos com a utilização do anticorpo monoclonal Biodesign (C86307M) usando três recuperações antigênicas

\begin{tabular}{|c|c|c|c|c|}
\hline \multirow[t]{2}{*}{ Caso no. } & \multicolumn{2}{|c|}{ Protease XIV } & \multirow{2}{*}{$\begin{array}{r}\text { Proteinase K } \\
1 / 500 \quad 1 / 1000\end{array}$} & Calor (Tampão Citrato) \\
\hline & $1 / 500$ & $1 / 1000$ & & $\begin{array}{ll}1 / 500 & 1 / 1000 \\
\end{array}$ \\
\hline
\end{tabular}

$\begin{array}{ccccccc}1 & 1^{\mathrm{a}} & 1 & 1 & 1 & 0 & 0 \\ 2 & 0^{\mathrm{b}} & 0 & 1 & 0 & 0 & 0 \\ 3 & 1 & 1 & 1 & 0 & 0 & 0 \\ 4 & 0 & 0 & 0 & 0 & 0 & 0 \\ 5 & 0 & 0 & 1 & 0 & 0 & 0 \\ 6^{\mathrm{c}} & 0 & 0 & 0 & 0 & 0 & 0\end{array}$

a Marcação leve, b ausência de marcação, ${ }^{c}$ controle negativo.

A digestão com protease XIV e proteinase $\mathrm{K}$ apresentaram baixa intensidade de marcação com os anticorpos monoclonais. O anticorpo GeneTex apresentou marcação leve nas recuperações antigênicas com protease XIV e proteinase $\mathrm{K}$ e $\mathrm{o}$ anticorpo Biodesign obteve melhor marcação quando utilizado proteinase $\mathrm{K}$, ambos na diluição de 1:500. A intensidade de marcação com o anticorpo GeneTex (GTX 21002) e Biodesign (C86307M) estão representados nos Quadros 2 e 3, respectivamente.

$\mathrm{Na}$ recuperação antigênica com calor e tampão citrato os dois anticorpos monoclonais apresentaram ausência

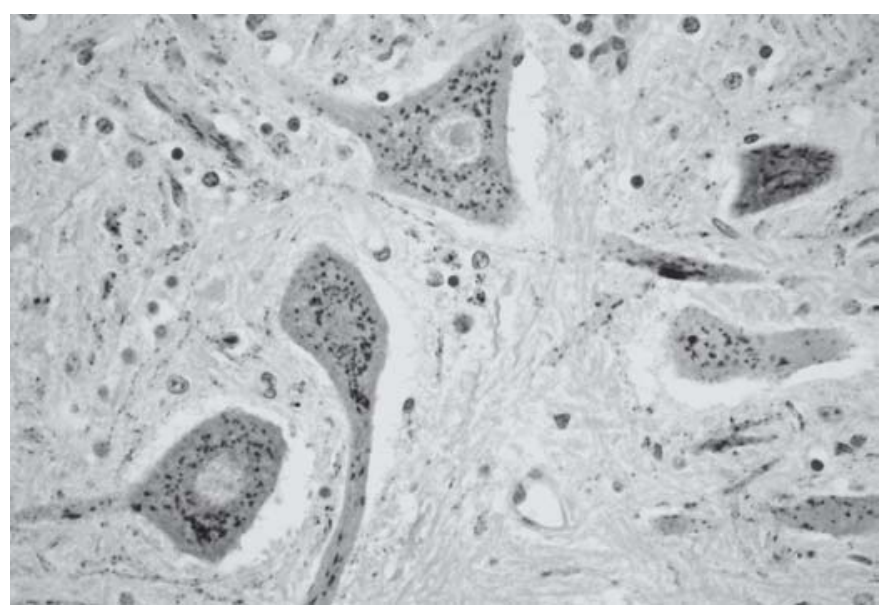

Fig. 3. Marcação acentuada de antígeno viral na forma de agregado de grânulos vermelhos em neurônios na medula espinhal. Anticorpo policlonal Chemicon 1:1000. Imuno-histoquímica pelo método biotina-estreptavidina-peroxidase e contra-corada com hematoxilina, obj.40x.

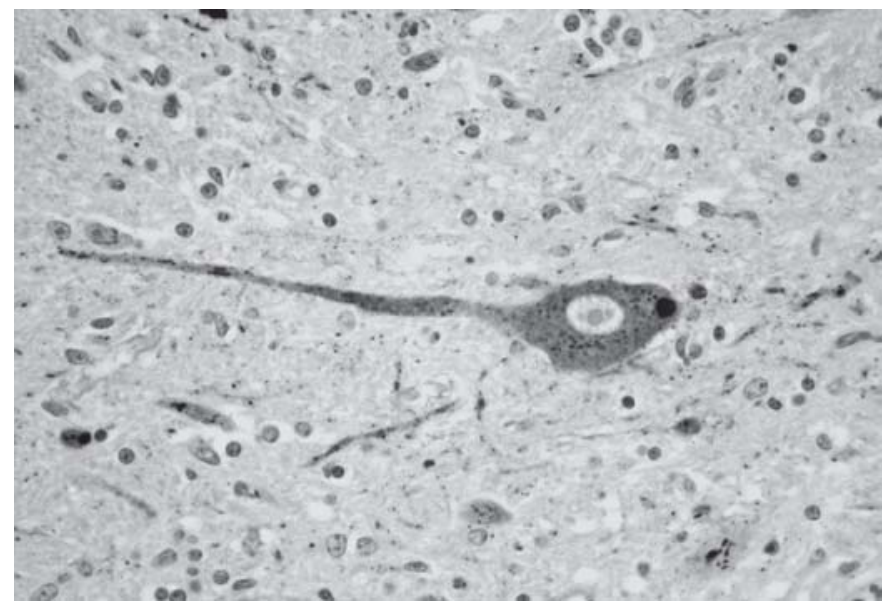

Fig.4. Identificação positiva de corpúsculo de inclusão viral única em neurônio fortemente marcado na medula espinhal. Anticorpo policlonal Chemicon 1:1000. Imuno-histoquímica pelo método biotina-estreptavidina-peroxidase e contra-corada com hematoxilina, obj.40x.

de marcação. Todos os casos que foram positivos na técnica de imuno-histoquímica demonstraram a presença do antígeno viral no citoplasma de neurônios na forma de agregados de grânulos (Fig.3) também na forma redonda ou oval, mostrando corpúsculo de inclusão viral único a múltiplos nos neurônios (Fig.4).

$\mathrm{Na}$ determinação da diluição do anticorpo policlonal anti-raiva, foram obtidos resultados positivos nas diluições de 1:500 e 1:1000. Perda na qualidade da identificação do antígeno de raiva foi visualizado quando os anticorpos foram diluídos a 1:1500. O bloqueio das reações inespecíficas mostrou-se bastante eficaz quando os cortes foram incubados com leite em pó desnatado (MolicoÒ) 5\% diluídos em água destilada durante 15 minutos.

\section{DISCUSSÃO}

O diagnóstico de raiva nas cinco amostras analisadas foi baseado no quadro clínico e nas lesões histopatológicas, sendo confirmados pelo teste de imunofluorescência direta para raiva e inoculação intracerebral em camundongo. A imuno-histoquímica se mostrou satisfatória para o diagnóstico de raiva a partir de fragmentos de sistema nervoso central destes casos. As cinco amostras de SNC utilizadas na padronização da técnica de imuno-histoquímica foram fixadas em formol $10 \%$ por um período que variou de 24 horas a uma semana. Trabalhos prévios sugerem que a fixação prolongada prejudica a detecção de antígenos virais (Ramos-Vara 2005).

Foi possível observar que o anticorpo policlonal empregado apresentou marcação mais intensa que os anticorpos monoclonais. Este resultado difere do que já foi relatado por outros autores (Hamir \& Moser 1994, Hamir et al. 1995). Os anticorpos policlonais em geral apresentam alta afinidade e ampla reatividade (Ramos-Vara 2005). A utilização de anticorpos policlonais possibilita que uma maior quantidade de epítopos seja marcada, uma vez que 
há uma grande variação na fonte de animais utilizados na produção de antígenos (Van Maanen et al. 2004). Estes são geralmente empregados nos testes de rotina de imunofluorescência direta pra raiva (Terra 2007).

A recuperação antigênica utilizando-se solução tampão citrato previamente aquecida em banho-maria a $100^{\circ} \mathrm{C}$ possibilitou intensa marcação com o anticorpo policlonal. Diversos métodos de recuperação antigênica usando calor têm sido utilizados em IHQ como autoclave (Bankfalvi et al. 1994), panela de pressão (Norton et al. 1994, Miller \& Estran 1995), forno de microondas (Gown et al. 1993, Cattoretti \& Suurmeijer 1995, Imam et al. 1995) e banhomaria (Kawai et al. 1994), com o objetivo de quebrar as ligações cruzadas e expor os epítopos para o reconhecimento do anticorpo primário (Puchtler \& Meloan 1985, Anthony et al. 1989, Shi et al. 1997). No presente estudo só foi usado banho-maria com a utilização de panela doméstica com água aquecida a $100^{\circ} \mathrm{C}$, apresentando excelente resultado. Machado et al. (2004) obteve bons resultados com a técnica de imuno-histoquímica para raiva utilizando tampão citrato com calor, porém usando forno de microondas seguido de digestão enzimática com tripsina $0,1 \%$.

As lâminas positivadas (ImmunoSlide-EasyPath) atraem eletrostaticamente as secções de tecido incluídas em parafina, aderindo-os melhor a lâmina e assim demonstraram ser melhores que lâminas preparadas com gelatina. Os cortes nestas últimas com freqüência se descolavam quando aquecidos para recuperação antigênica em microondas e banho-maria.

A imuno-histoquímica é um método rápido, podendo ser usado na rotina em casos onde inicialmente há suspeita de raiva (Machado et al. 2004), especialmente em casos onde fragmentos de cérebro submetidos ao laboratório foram fixados em formol, impossibilitando a realização da imunofluorescência direta ou a inoculação intracerebral em camundongos. Por vezes a detecção de antígenos do vírus da raiva por imuno-histoquímica tem sido relatada mesmo em tecido nervoso em processo de autólise (Arslan et al. 2004). Estudos feitos com materiais deteriorados comprovaram que o primeiro exame que resulta em falso negativo é a detecção dos corpúsculos de Negri, seguido pela inoculação em camundongos e, por último, a imunofluorescência direta (Fernandes \& RietCorrea 2007). A imuno-histoquímica permite o uso de tecidos fixados em formol, o que possibilita o envio das amostras ao laboratório quando condições de refrigeração e transporte são inadequadas (Hamir \& Moser 1994). A imuno-histoquímica pode ser também usada, particularmente em estudos retrospectivos, quando tecidos frescos ou congelados não podem ser avaliados ou quando as amostras não podem ser enviadas ao laboratório imediatamente. (Arslan et al. 2004).

Os resultados do presente trabalho demonstram que a técnica de imuno-histoquímica para raiva utilizando-se anticorpo primário policlonal Chemicon \#5199 apresentou excelentes resultados quando tratados com calor e solução de tampão citrato na recuperação antigênica. A utilização deste anticorpo policlonal associado à recuperação antigênica com tampão citrato em banho-maria demonstrou também vantagem econômica visto que os materiais empregados foram de menor custo quando comparados com outros protocolos. Proporcionou também economia de tempo, pois com os dois anticorpos monoclonais e recuperação antigênica com protease XIV e proteinase $\mathrm{K}$ necessitou-se deixar "overnight", aumentando o tempo para finalizar o diagnóstico. A imuno-histoquímica é uma ferramenta importante de diagnóstico de rotina laboratorial, especialmente quando o SNC é submetido fixado em formol $10 \%$, impossibilitando a realização de provas de imunofluorescência direta e inoculação intracerebral em camundongos, além de, solucionar casos de meningoencefalite não-específica sem a presença de corpúsculos de inclusão.

Agradecimentos.- À Professora Mary Suzan Varaschin da Universidade Federal de Lavras pelas amostras de SNC de bovinos com raiva. Às técnicas de Laboratório Ângela Belmonte de Souza e Marília de Oliveira Belmonte pela confecção do material de estudo. Aos colegas do Setor de Patologia Veterinária da UFRGS pela valiosa ajuda deste trabalho. À Coordenação de Aperfeiçoamento de Pessoal de Nível Superior (CAPES), pela concessão de bolsa de mestrado e ao Conselho Nacional de Desenvolvimento Científico e Tecnológico (CNPq).

\section{REFERÊNCIAS}

Anthony S., Leong Y. \& Gilham P.N. 1989. The effects of progressive formaldehyde fixation on the preservation of tissue antigens. Pathol. 21:266-268.

Arslan A., Saglam Y.S. \& Temur A. 2004. Detection of rabies viral antigens in non-autolysed and autolysed tissues by using an immunoperoxidase technique. Vet. Rec. 155:550-552.

Bankfalvi A., Navabi H., Bier B., Böcker W., Jasani B. \& Schmid K.W. 1994. Wet autoclave pretreatment for antigen retrieval in diagnostic immunohistochemistry. J. Pathol. 174:223-228.

Cattoretti G. \& Suurmeijer A.J.H. 1995. Antigen unmasking on formalinfixed paraffin-embedded tissues using microwaves: A review. Adv. Anat. Pathol. 2:2-9.

Consales C.A. \& Bolzan V.L. 2007. Rabies review: immunopathology, clinical aspects and treatment. J. Venom. Anim. Toxins Trop. Dis. 13:5-38.

Côrtes V.A., Paim G.V. \& Oliveira M.C.G. 1979. Diagnóstico da raiva canina. Revta Saúde Pública 13:353-356.

Fernandes C.G. \& Riet-Correa F. 2007. Raiva, p.184-198. In: Riet-Correa F., Schild A.L., Lemos R.A.A. \& Borges J.R.J. (Ed.), Doenças de Ruminantes e Eqüídeos. Vol.1. Pallotti, Santa Maria. 719p.

George L.W. 1993. Moléstias do sistema nervoso, p.901-1039. In: Smith B.P. (Ed.), Tratado de Medicina Interna de Grandes Animais. Vol.2. Manole, São Paulo. 1738p.

Germano P.M.L., Miguel O. \& Chamelet E.L.B. 1977. Estudo comparativo entre as técnicas de coloração de Sellers, imunofluorescência direta e inoculação em camundongos, aplicadas ao diagnóstico laboratorial da raiva canina. Revta. Fac. Med. Vet. Univ. São Paulo 14:133141.

Gown A.M., Wever N. \& Battifora H. 1993. Microwave-based antigenic unmasking. Appl. Immunohistochem. 1:256-266.

Hamir A.N. \& Moser G. 1994. Immunoperoxidase test for rabies: utility as a diagnostic test. J. Vet. Diagn. Invest. 6:148-152.

Hamir A.N., Moser G., Fu Z.F., Dietzschold B. \& Rupprecht C.E. 1995. 
Immunohistochemical test for rabies: Identification of a diagnostically superior monoclonal antibody. Vet. Rec. 136:295-296.

Imam S.A., Young L., Chaiwun B. \& Taylor C.R. 1995. Comparison of two microwave based antigen-retrieval solutions in unmasking epitopes in formalin-fixed tissue for immunostaining. Anticancer Res. 15:11531158.

Jones T.C., Hunt R.D. \& King N.W. 2000. Patologia Veterinária. 6ª ed. Manole, São Paulo. 1415p.

Jubb K.V.F. \& Huxtable C.R. 1993. The nervous system, p.267-437. In: Jubb K.V.F., Kennedy P.C. \& Palmer N. (Ed.), Pathology of Domestic Animals. Vol.1. $4^{\text {th }}$ ed. Academic Press, San Diego.

Kawai A., Serizawa A. \& Tsutsumi Y. 1994. Heat-induced antigen retrieval of proliferating cell nuclear antigen and p53 protein in formalin-fixed, paraffin-embedded sections. Pathol. Int. 44:759-764.

Langohr I.M., Irigoyen L.F., Lemos R.A.A. \& Barros C.S.L. 2003. Aspectos epidemiológicos, clínicos e distribuição das lesões histológicas no encéfalo de bovinos com raiva. Ciência Rural 33:125-131.

Lima E.F., Riet-Correa F., Castro R.S., Gomes A.A.B. \& Lima F.S. 2005 Sinais clínicos, distribuição das lesões no sistema nervoso e epidemiologia da raiva em herbívoros na região Nordeste do Brasil. Pesq. Vet. Bras. 25:250-264.

Machado G.F., Silva L.H.Q. \& Nunes C.M. 2004. Detecção de antígenos do vírus da raiva em encéfalos de cão mantido em formol durante longo período. Revta Port. Ciênc. Vet. 99:89-92.

Miller R.T. \& Estran C. 1995. Heat-induced epitope retrieval with a pressure cooker-suggestions for optimal use. Appl. Immunohistochem. 3:190-193.

Norton A.J., Jordan S. \& Yeomans P. 1994. Brief, high temperature heat denaturation (pressure cooking): a simple and effective method of antigen retrieval for routinely processed tissues. J. Pathol. 173:371379.
Puchtler H. \& Meloan S.N. 1985. On the chemistry of formaldehyde fixation and its effects on immunohistochemical reactions. Histochem. 82:201-204.

Prophet E.B., Mills B., Arrington J.B. \& Sobin L.H. 1992. Laboratory Methods in Histotechnology. Armed Forces Institute of Pathology, American Registry of Pathology, Washington, DC. 279p.

Ramos-Vara J.A. 2005. Technical aspects of immunohistochemistry. Vet. Pathol. 42:405-426.

Rech R.R. 2007. Alterações no encéfalo de bovinos submetidos à vigilância das encefalopatias espongiformes transmissíveis. Tese de Doutorado, Universidade Federal de Santa Maria, Santa Maria, RS. 228p.

Shi S., Cote R.J. \& Taylor C.R. 1997. Antigen retrieval immunohistochemistry: past, present, and future. J. Histochem. Cytochem. 45:327-343.

Swanepoel R. 2004. Rabies, p.1123-1182. In: Coetzer J.A.W. \& Tustin R.C. (Ed.), Infectious Diseases of Livestock. Vol.2. $2^{\text {nd }}$ ed. Oxford University Press, Cape Town. 795p.

Terra S.A. 2007. Características das encefalites em autópsias - aspectos epidemiológicos e morfológicos. Tese de Doutorado, Universidade Federal do Triângulo Mineiro, Uberaba. 106p.

Van Maanen C., Wouda W., Schares G., Von Blumröder D., Conraths F.J., Norton R., Williams D.J.L., Esteban-Redondo I., Innes E.A., Mattsson J.G., Björkman C., Fernández-García A., Ortega-Mora L.M., Müller N., Sager H. \& Hemphill A. 2004. An interlaboratory comparison of immunohistochemistry and PCR methods for detection of Neospora caninum in bovine foetal tissues. Vet. Parasitol. 126:351-364.

Woldehiwet Z. 2002. Rabies: recent developments. Res. Vet. Sci. 73:1725.

Zimmer K., Wiegand D., Manz D., Frost J.W., Reinacher M. \& Frese K. 1990. Evaluation of five different methods for routine diagnosis of rabies. Zentralbl. Veterinärmed B 37:392-400. 